\title{
Is Isolation of Human Herpesvirus 6 in Kidney Transplant Recipients Clinically Significant?
}

\section{Theodoros Kelesidis*}

Department of Medicine, Division of Infectious Diseases, David Geffen School of Medicine, University of California, Los Angeles, USA

Human herpesvirus-6 (HHV-6), a ubiquitous $\beta$-herpesvirus that can infect the majority of humans, has been recognized as a cause of infection in kidney transplant recipients for more than 20 years now [1]. The incidence of HHV-6 infection varies widely, depending on the study and method of testing and is estimated to be $23-55 \%$ in kidney transplant recipients [2,3]. After primary infection, HHV-6 persists in a latent state in the host in various cells, mainly in those of monocyte and macrophage origin [4] and can reactivate later in life, especially after transplantation. The incidence of HHV-6 reactivation peaks at 2-4 weeks after transplantation, but late infections that occur months or years after transplantation may occur [1,5]. Infection is most likely to result from reactivation of recipient's endogenous HHV-6 but the virus may also be transmitted through organ transplantation [5]. Kidney transplant recipients receiving an allograft from the same donor can have the same HHV-6 isolate [2]. Thus, HHV-6 may be transmitted with the donor kidney allograft and reactivation after transplantation could be attributable to the HHV- 6 strain of either the recipient or donor origin.

HHV-6 may persist in kidney allografts [6]. HHV-6 specific antigens have been detected by immunohistochemistry in kidney biopsies of patients with acute and chronic rejection or cyclosporine-related nephropathy while high viral loads in renal tissue have been correlated with significant illness owing to HHV-6 infection of pediatric kidney transplant patients [1,5,7]. Nucleic acid testing has also allowed for detection of chromosomally integrated HHV-6 (CIHHV-6) in kidney transplant recipients [8]. However the significance of the persistent HHV-6 regarding transplant outcome remains uncertain [8].

In addition to the direct effects of HHV-6, numerous indirect effects have also been reported or suggested since HHV- 6 is considered to be an immunomodulatory virus $[1,5]$. HHV -6 has been associated with a higher risk of CMV disease, and concomitant or recent CMV infection may induce the clinical symptoms [9]. Concurrent intragaft infections of HHV-6 and CMV have been found both in kidney transplants [6]. Finally, both HHV-6 and HHV-7 infections are associated with the development of chronic allograft nephropathy [10].

Although HHV-6 infection in kidney transplant recipients is mostly subclinical, symptomatic or even fatal HHV-6 infections have been described. Pure HHV-6 infections are limited to small case series describing fever, elevated creatinine levels, liver dysfunction, and colitis $[1,5]$. The few fatal cases of HHV-6 disease were characterized by hemophagocytic syndrome, encephalitis, pancytopenia, severe hepatitis, or colitis [11].

The diagnosis of clinically significant HHV-6 infection is challenging. HHV-6 infections after kidney transplantation were mainly diagnosed based on serological analysis or isolation of the virus from blood specimens and were usually asymptomatic [12]. Serology has limited diagnostic value due to high seroprevalence rate (over 95\%) in adult transplant patients. Viral culture of HHV-6 is laborious, is not routinely used in diagnostic laboratories, and the turn-around time is too slow to be of use in guiding the management in real-time clinical practice. Recently, several virus detection methods have been developed, that demonstrate the presence of HHV- 6 in the tissue specimens [13].
Detection of HHV-6 in the clinical specimen does not necessarily implicate the virus as the etiology of a specific illness, and the differentiation between latent and active infection is not always possible. Demonstration of HHV-6 specific antigens in tissue specimens may be more informative than the demonstration of viral DNA in the blood [13]. Quantitative methods are needed to diagnose an active systemic HHV-6 infection and the quantification of HHV-6 DNA using realtime PCR, is currently the most common tool to diagnose an active HHV-6 infection [13]. However the methods are not standardized and no clear cut-off levels exist to differentiate asymptomatic viral replication from symptomatic clinical disease. Finally although novel molecular methods for the detection of HHV-6 have been developed to distinguish between latent and active infection in transplant patients, these tests are not in general use [8].

In conclusion, HHV-6 is a common infection after kidney transplantation. However, HHV-6 diagnostics is not routinely performed and the clinical role of HHV- 6 infection might be underestimated. Although the reactivation rate is high, clinical disease is estimated to occur in only $1 \%$ of patients. Although HHV- 6 surveillance after transplantation is not routinely performed in clinical practice, the diagnosis of HHV-6 is now commonly made using nucleic acid testing. Antiviral prophylaxis and preemptive therapy are not recommended for HHV-6 [5]. Foscarnet, ganciclovir, and cidofovir may be used for treatment in established end-organ disease such as encephalitis [5]. Current diagnostic methods need to be standardized whereas larger prospective studies with long durations of follow-up are needed to evaluate the significance of isolation of HHV-6 in kidney transplant recipients.

\section{References}

1. Morris DJ, Littler E, Arrand JR, Jordan D, Mallick NP, et al. (1989) Human herpesvirus 6 infection in renal-transplant recipients. N Engl J Med 320: 1560 1561.

2. Yoshikawa T, Suga S, Asano Y, Nakashima T, Yazaki T, et al. (1992) A prospective study of human herpesvirus- 6 infection in renal transplantation. Transplantation 54: 879-883.

3. Herbein G, Strasswimmer J, Altieri M, Woehl-Jaegle ML, Wolf P, et al. (1996) Longitudinal study of human herpesvirus 6 infection in organ transplant recipients. Clin Infect Dis 22: 171-173.

4. Luppi M, Barozzi P, Bosco R, Vallerini D, Potenza L, et al. (2006) Human herpesvirus 6 latency characterized by high viral load: chromosomal integration in many, but not all, cells. J Infect Dis 194: 1020-1021.

*Corresponding author: Theodoros Kelesidis, MD, Department of Medicine, Division of Infectious Diseases, David Geffen School of Medicine, University of California, 37-121 Center for Health Sciences, 10833 LeConte Avenue, Los Angeles, CA 90095, USA, Tel: 310-825-7225; Fax: 310-825-3632; E-mail: tkelesidis@mednet.ucla.edu

Received April 18, 2012; Accepted April 23, 2012; Published April 28, 2012

Citation: Kelesidis T (2012) Is Isolation of Human Herpesvirus 6 in Kidney Transplant Recipients Clinically Significant? J Transplant Technol Res 2:e111. doi:10.4172/2161-0991.1000e111

Copyright: (c) 2012 Kelesidis T. This is an open-access article distributed under the terms of the Creative Commons Attribution License, which permits unrestricted use, distribution, and reproduction in any medium, provided the original author and source are credited. 
Citation: Kelesidis T (2012) Is Isolation of Human Herpesvirus 6 in Kidney Transplant Recipients Clinically Significant? J Transplant Technol Res 2:e111. doi:10.4172/2161-0991.1000e111

Page 2 of 2

5. De Bolle L, Naesens L, De Clercq E (2005) Update on human herpesvirus 6 biology, clinical features, and therapy. Clin Microbiol Rev 18: 217-245.

6. Helantera I, Loginov R, Koskinen P, Lautenschlager I (2008) Demonstration of HHV-6 antigens in biopsies of kidney transplant recipients with cytomegalovirus infection. Transpl Int 21: 980-984.

7. Gupta M, Diaz-Mitoma F, Feber J, Shaw L, Forget C, et al. (2003) Tissue HHV6 and 7 determination in pediatric solid organ recipients--a pilot study. Pediatr Transplant 7: 458-463.

8. Lee SO, Brown RA, Razonable RR (2012) Chromosomally integrated human herpesvirus- 6 in transplant recipients. Transpl Infect Dis.

9. DesJardin JA, Gibbons L, Cho E, Supran SE, Falagas ME, et al. (1998) Human herpesvirus 6 reactivation is associated with cytomegalovirus infection and syndromes in kidney transplant recipients at risk for primary cytomegalovirus infection. J Infect Dis 178: 1783-1786.
10. Chapenko S, Folkmane I, Ziedina I, Chistyakovs M, Rozentals R, et al. (2009) Association of HHV-6 and HHV-7 reactivation with the development of chronic allograft nephropathy. J Clin Virol 46: 29-32.

11. Pilmore H, Collins J, Dittmer I, Williams L, Carpenter L, et al. (2009) Fata human herpesvirus- 6 infection after renal transplantation. Transplantation 88 762-765.

12. Kikuta H, Itami N, Matsumoto S, Chikaraishi T, Togashi M (1991) Frequent detection of human herpesvirus 6 DNA in peripheral blood mononuclear cells from kidney transplant patients. J Infect Dis 163: 925.

13. Flamand L, Komaroff AL, Arbuckle JH, Medveczky PG, Ablashi DV (2010) Review, part 1: Human herpesvirus-6-basic biology, diagnostic testing, and antiviral efficacy. J Med Virol 82: 1560-1568. 